\title{
Archives Of Breast

DOI: 10.32768/abc.20229166-75

\section{Anti-Proliferative And Pro-Apoptotic Effects Of Dipsacus Asperoides in a Cellular Model for Triple-Negative Breast Cancer}

\author{
Nitin Telang*a, Hareesh B Nair ${ }^{b}$, George YC Wong ${ }^{c, d}$ \\ aCancer Prevention Research Program, Palindrome Liaisons Consultants, Montvale, New Jersey, USA \\ bUniversity of Texas Health Science Center, San Antonio, Texas, USA \\ ${ }^{c}$ American Foundation for Chinese Medicine, New York city, New York, USA
}

${ }^{d}$ Breast Center, Maimonides Medical Center, Brooklyn, New York, USA

ARTICLE INFO

Received:

04 August 2021

Revised:

20 November 2021

Accepted:

26 November 2021

Keywords:

Breast cancer,

Dipsacus asperoides,

Pro-apoptotic,

TNBC

\section{ABSTRACT}

Background: Triple negative breast cancer (TNBC) lacks expressions of estrogen receptor- $\alpha(E R-\alpha)$, progesterone receptor (PR) and amplified human epidermal growth factor receptor-2 (HER2). Current treatment for TNBC includes anthracyclin, taxol and cisplatin-based conventional chemotherapy and survival pathway PARP, PI3K, AKT and mTOR selective targeted therapy. These treatments exhibit dose-limiting systemic toxicity and presence of drug resistant cancer stem cells, which highlight the need for identification of efficacious testable alternatives that are not toxic to non-tumorigenic cells. Dipsacus asperoides (DA) is a Chinese nutritional herb and its root represents a common ingredient in Chinese herbal formulations used in women for estrogen related health issues, osteoporosis and breast diseases. This study aims to investigate the growth inhibitory effects of DA, and to detect mechanisms for its efficacy.

Methods: Human mammary carcinoma derived triple negative MDA-MB-231 cell line represented the TNBC model. Non-fractionated aqueous extract from DA represented the test agent. Anchorage dependent growth, anchorage independent (AI) colony formation and cell cycle progression quantified growth inhibition. Western blot-based analysis for inhibition of RAS, PI3K and AKT and RB signaling identified mechanistic leads.

Results: Treatment with DA induced a dose dependent cytostatic growth arrest $\left(\mathrm{IC}_{50}: 15 \mu \mathrm{g} / \mathrm{ml}\right.$; IC 90 : $30 \mu \mathrm{g} / \mathrm{ml}$ ), reduced AI growth and inhibited cell cycle progression via $\mathrm{G}_{2} / \mathrm{M}$ arrest. DA affected the RAS, PI3K, AKT and RB signaling pathways, and functioned as a natural inhibitor of cyclin dependent kinase 4/6. Cellular apoptosis paralleled increase in pro-apoptotic Caspase 3/7 activity.

Conclusion: These results demonstrate that DA inhibited growth, affected cell cycle progression, induced apoptosis and inhibited cancer cell survival pathways. This study validates a mechanism-based approach to identifying testable substitutes for secondary prevention/therapy of TNBC.

Copyright $($ 2022. This is an open-access article distributed under the terms of the Creative Commons Attribution-Non-Commercial 4.0 International License, which permits copy and redistribution of the material in any medium or format or adapt, remix, transform, and build upon the material for any purpose, except for commercial purposes.

\footnotetext{
*Address for correspondence:

Nitin Telang, PhD

Cancer Prevention Research Program, Palindrome Liaisons Consultants, Montvale, New Jersey, USA

Tel: +1 646.512.3277

Email: ntelang3@gmail.com
}

\section{INTRODUCTION}

The American Cancer Society estimates 281,550 new breast cancer cases and 43,600 deaths due to breast cancer in women in 2022. The death rates are attributed to advanced breast cancers showing distant metastasis and resistance to conventional and/or mole- 
cular therapy. ${ }^{1}$ The triple negative breast cancer (TNBC) is an aggressive molecular subtype with no expression of ER- $\alpha$, PR and amplified HER2, and, therefore, is resistant to conventional endocrine or HER2 targeted therapy. ${ }^{2,3}$ Current treatment consists of anthracyclin, taxol and platinum-based convent-ional chemotherapy, and survival pathway selective poly (ADP-ribose) polymerase (PARP), phosphoin-ositide3 kinase (PI3K) and mammalian target of rapa-mycin (m-TOR) inhibitor-based targeted therapy.,5 These treatments cause long-term dose-limiting systemic toxicity, de novo or acquired tumor resist-ance, and appearance of drug resistant cancer stem cells affecting therapeutic efficacy and causing disease progression. ${ }^{6}$ Thus, these limitations highlight the need for identification of new and less toxic treatment choices which are testable.

Traditional Chinese herbal formulations consisting of several nutritional herbs are used in women for estrogenrelated issues, osteoporosis and breast diseases. ${ }^{7-10}$ Chinese nutritional herbs exhibiting minimal systemic toxicity in vivo and effective growth inhibition of cancer cells should offer testable alternatives as novel approaches to potential secondary prevention/therapy of chemo-endocrine therapy resistant breast cancer.

Several Chinese nutritional herbs that function via distinct mechanisms of action exhibit growth inhibitory effects in cellular models for the ER- $\alpha$ positive, PR positive, and HER2 negative (Luminal A) and ER$\alpha$ negative, PR negative and HER2 negative (triple negative) molecular subtypes of breast cancer. ${ }^{11-17}$ Additionally, published evidence from a comparative study on isogenic MCF-7 phenotypes with modulated ER- $\alpha$ function has demonstrated that the Chinese nutritional herb Dipsacus asperoides (DA) exhibits essentially similar growth inhibitory effects for the phenotypes with functional or non-functional ER- $\alpha .^{15}$ To extend and confirm the concept of novel testable alternatives in TNBC, this study sought to examine the growth inhibitory effects of DA, and to identify potential mechanisms for its efficacy in the MDA-MB231 model.

\section{METHODS}

\section{Experimental Model}

The human breast carcinoma derived MDA-MB231 cell line was taken from American Type Culture Collection (ATCC, Manassas, VA, USA). This cell line does not have the expression of ER- $\alpha$, PR and of amplified HER2, ${ }^{18,19}$ and therefore, constitutes a cellular model for TNBC. The MDA-MB-231 cells were cultured in RPMI medium with L-glutamine and 5\% fetal bovine serum (Life Technologies, Grand Island, NY) following the vendor's protocol.

\section{Dose Response of DA}

The stock solution for the non-fractionated aqueous extract for DA was prepared based on the published protocol. ${ }^{13,14}$ Briefly, 20g of DA roots were boiled in $200 \mathrm{ml}$ of deionized water to reduce the volume to $100 \mathrm{ml}$, and the $500 \mathrm{xg}$ supernatant was collected (Extract I). The resulting residue was boiled in $100 \mathrm{ml}$ of deionized water to reduce the volume to $50 \mathrm{ml}$, and the 500xg supernatant was collected (Extract II). The two extracts were combined and boiled to reduce the volume to $25 \mathrm{ml}$. Twenty $\mathrm{ml}$ of the $500 \mathrm{xg}$ supernatant represented the $100 \%$ non-fractionated aqueous extract, which was diluted in the culture medium to obtain a concentration of $1 \mathrm{mg} / \mathrm{ml}$ representing the stock solution. This stock solution was serially diluted using the culture medium to obtain the concentration range of $10 \mu \mathrm{g} / \mathrm{ml}$ to $50 \mu \mathrm{g} / \mathrm{ml}$. For the dose response experiments, $5 \times 10^{3}$ MDA-MB-231 cells were seeded in 96-well plates and treated hours later with DA at the concentrations of $10 \mu \mathrm{g} / \mathrm{ml}, 20 \mu \mathrm{g} / \mathrm{ml}, 40 \mu \mathrm{g} / \mathrm{ml}$ and $50 \mu \mathrm{g} / \mathrm{ml}$. The control cells were maintained in the culture medium (untreated control). The cultures were maintained for 7 days at $37^{\circ} \mathrm{C}$ in a $\mathrm{CO}_{2}$ incubator. The medium was replenished after the first 3 days with fresh medium containing relevant concentrations of DA for the treated groups. Cell viability was determined on day 7 after seeding by Cell Titre Glo 2.0 assay (Promega Corporation, Madison, WI, USA) as recommended in the vendor's protocol. The data from the dose response experiments were extrapolated to determine the minimally effective inhibitory $\mathrm{IC}_{25}$, halfmaximal $\mathrm{IC}_{50}$ and maximally cytostatic $\mathrm{IC}_{90}$ concentrations of DA.

\section{Anchorage independent (AI) Growth}

For this assay, a 6\% stock solution of agar was prepared by dissolving DNA grade agar (SigmaAldrich-Merk K Ga A) with an appropriate volume of 2X RPMI medium. To prepare the basement layer, this stock solution was diluted to $0.6 \%$ with 2 XRPMI medium, dispersed in a 6-well plate and allowed to solidify overnight at $37^{\circ} \mathrm{C}$. MDA-MB-231 cell suspension, at a density of $5 \times 10^{5}$ per $\mathrm{ml}$, was prepared in RPMI medium containing $0.33 \%$ agar, and was overlaid on the basement layer in the presence of $2.5 \mu \mathrm{g} / \mathrm{ml}, 15.0 \mu \mathrm{g} / \mathrm{ml}$ and $30.0 \mu \mathrm{g} / \mathrm{ml}$ of DA, equivalent to $\mathrm{IC}_{25}, \mathrm{IC}_{50}$ and $\mathrm{IC}_{90}$, respectively (treatment group). Cell suspension in the culture medium represented the untreated control group. The cultures were incubated at $37^{\circ} \mathrm{C}$ in a $\mathrm{CO}_{2}$ incubator for 21 days. The $\mathrm{AI}$ colonies were fixed overnight in $4 \%$ phosphate buffered formaldehyde (Sigma-Aldrich), stained with $0.005 \%$ crystal violet (Sigma-Aldrich), and colony counts were determined at 10x magnification. 


\section{Cell Cycle Progression}

For the analysis of cell cycle, $5 \times 10^{4}$ cells were seeded in T-25 flasks and treated for $24 \mathrm{~h}$ post-seeding with $2.5,15.0$ and $30.0 \mu \mathrm{g} / \mathrm{ml}$ concentrations of DA for 48h. The cells were harvested by trypsinization, pelleted at 500xg at room temperature, and washed twice with cold phosphate buffered saline (PBS, Sigma-Aldrich). The cells were then fixed with cold $70 \%$ ethanol, washed with cold PBS, and stained with $50 \mu \mathrm{g} / \mathrm{ml}$ propidium iodide (PI, Sigma-Aldrich) dissolved in PBS. Subsequently, the cells were incubated with $10 \mu \mathrm{g} / \mathrm{ml}$ ribonuclease A (SigmaAldrich) at $37^{\circ} \mathrm{C}$ for $20 \mathrm{mins}$, followed by overnight incubation at $4^{\circ} \mathrm{C}$ in the dark. DNA content was determined by flow cytometry using Becton Dickinson FACSCAN Flow Cytometer (BD Biosciences, Research Triangle Park, NC, USA) and analyzed using FCS Express software version 306 (De Novo Software, Pasadena, CA, USA) to determine the individual cell population in Sub $\mathrm{G}_{0}$ (apoptotic), $\mathrm{G}_{1}$ (quiescent), $\mathrm{S}$ and $\mathrm{G}_{2} / \mathrm{M}$ (proliferative) phases of the cell cycle. The data were presented as \% cell population in Sub $G_{0}, G_{1}$ and $\mathrm{G}_{2} / \mathrm{M}$ phases of the cell cycle.

Table 1. Source of antibodies
Western Blot Analysis

For these experiments, cells were seeded in $10 \mathrm{~cm}$ dishes at $70 \%$ confluence one day before the treatment. The cultures were treated with $10 \mu \mathrm{g} / \mathrm{ml}\left(\mathrm{IC}_{30}\right)$ and $15 \mu \mathrm{g} / \mathrm{ml}\left(\mathrm{IC}_{50}\right)$ of DA, and were incubated for $48 \mathrm{~h}$ in a $\mathrm{CO}_{2}$ incubator at $37^{\circ} \mathrm{C}$. Cells were harvested and immediately lysed with radio-immunoprecipitation assay (RIPA) buffer containing protease inhibitors (Sigma-Aldrich), and centrifuged for 15 minutes at $10,000 \times \mathrm{g}$ at $4^{\circ} \mathrm{C}$. The protein content of the lysate was determined by the Bradford method and an equal quantity of proteins were separated on $10 \%$ SDSPAGE precast mini gels (Mini-PROTEAN TGX, BioRad Laboratories, Hercules, CA, USA). The separated proteins were transferred onto a nitrocellulose membrane (Bio-Rad Laboratories), blocked at $4^{\circ} \mathrm{C}$ overnight with 5\% nonfat dry milk, and incubated with relevant primary and secondary antibodies (Table 1). The chemo-luminescent signal was developed with ECL-plus reagent (Bio-Rad Laboratories), and detected by autoradiography. The signal intensity in the gels was quantified from the densitometric scans as arbitrary scanning units (ASU) using Molecular Image GS800 and Quantity One software (Bio-Rad. Laboratories).

\begin{tabular}{cccc}
\hline Antibody & Vendor & Catalog number & Dilution \\
\hline BRAF & SC & SC136263 & $1: 200$ \\
MEK & SC & SC365800 & $1: 100$ \\
ERK & SC & SC271269 & $1: 100$ \\
pERK & SC & SC81492 & $1: 200$ \\
PI3K 110 & SC & SC8010 & $1: 1500$ \\
pPI3K $\alpha$ & TF & MA538365 & $1: 1000$ \\
AKT & CST & 9272 & $1: 2000$ \\
pAKT & CST & 4060 & $1: 100$ \\
RB & SC & SC74562 & $1: 100$ \\
pRB (Ser780) & CST & 3590 & $1: 100$ \\
pRB (Ser780) & CST & 3590 & $1: 100$ \\
CDKI p21 & SC & SC 271532 & $1: 1000$ \\
CDK4 & CST & 12790 & $1: 200$ \\
CDK6 & CST & 7961 & $1: 200$ \\
\hline IgG-HRP & SC & 47778 & $1: 1000$ \\
\hline
\end{tabular}

SC, Santa Cruz Biotechnology; TF, Thermo-Fisher; CST, Cell Signaling technology; HRP, Horseradish peroxidase (Conjugate).

\section{Caspase Activity}

Caspase-3/7 activity was measured using CaspaseGlo assay kit (Promega Corporation). The cells were treated with $15 \mu \mathrm{g} / \mathrm{ml}$ and $30 \mu \mathrm{g} / \mathrm{ml}$ DA for $48 \mathrm{~h}$ DA treated cells were homogenized by sonication in a homogenization buffer (25mmol/l HEPES, pH 7.5, $5 \mathrm{mmol} / \mathrm{l} \mathrm{MgCl}_{2}$, and $1 \mathrm{mmol} / \mathrm{l}$ EGTA) and protease inhibitors (all from Sigma-Aldrich). The homogenate was centrifuged at $6,500 \mathrm{xg}$ at $4^{\circ} \mathrm{C}$ for 15 minutes. To $10 \mu \mathrm{l}$ of the supernatant, an equal volume of the assay reagent was added and this mixture was incubated at room temperature for $2 \mathrm{~h}$ The luminescence of the samples was measured using a Fluoroskan Luminometer (Thermo Scientific Co, Waltham, MA, 
USA). The data were expressed as relative luminescent units (RLU).

Statistical Analysis

The experiments for dose response, anchorage independent growth, cellular apoptosis and Caspase 3/7 activity were conducted in triplicate. The data were expressed as mean \pm SD. Statistically significant differences between the control and the multiple treatment groups were determined by one-way analysis of variance and Dunnett's test as a post-hoc test with a threshold of $\alpha=0.05$ using the Microsoft Excel 2013 XLSTAT-Base software.

\section{RESULTS}

Regarding the dose response of DA, a dose response experiment was conducted on the human breast carcinoma-derived MDA-MB-231 cells which is presented in Figure 1A. The DA treated cells exhibited a dose dependent decrease in \% cell viability at the 7-day time point. The data from these experiments were extrapolated to identify $\mathrm{IC}_{25}$ as 2.5 $\mu \mathrm{g} / \mathrm{ml}, \mathrm{IC}_{50}$ as $15 \mu \mathrm{g} / \mathrm{ml}$, and $\mathrm{IC}_{90}$ as $30 \mu \mathrm{g} / \mathrm{ml}$. In contrast, the dose response of DA on the nontumorigenic triple negative 184-B5 human mammary epithelial cells identified $\mathrm{IC}_{25}$ as $55 \mu \mathrm{g} / \mathrm{ml}, \mathrm{IC}_{50}$ as $70 \mu \mathrm{g} / \mathrm{ml}$ and $\mathrm{IC}_{90}$ as $126 \mu \mathrm{g} / \mathrm{ml}$.

Concerning the effect of DA on AI growth, the data presented in Figure 1B demonstrate that in response to treatment with the pre-determined concentrations of DA, the number of AI colonies exhibited a progressive decrease. The DA-induced inhibition ranged from $26.1 \%(\mathrm{P}=0.020)$ to $91.7 \%(\mathrm{P}=0.001)$, relative to the control group. These data identified $\mathrm{IC}_{50}$ as $13 \mu \mathrm{g} / \mathrm{ml}$, and $\mathrm{IC}_{90}$ as $29 \mu \mathrm{g} / \mathrm{ml}$, respectively.
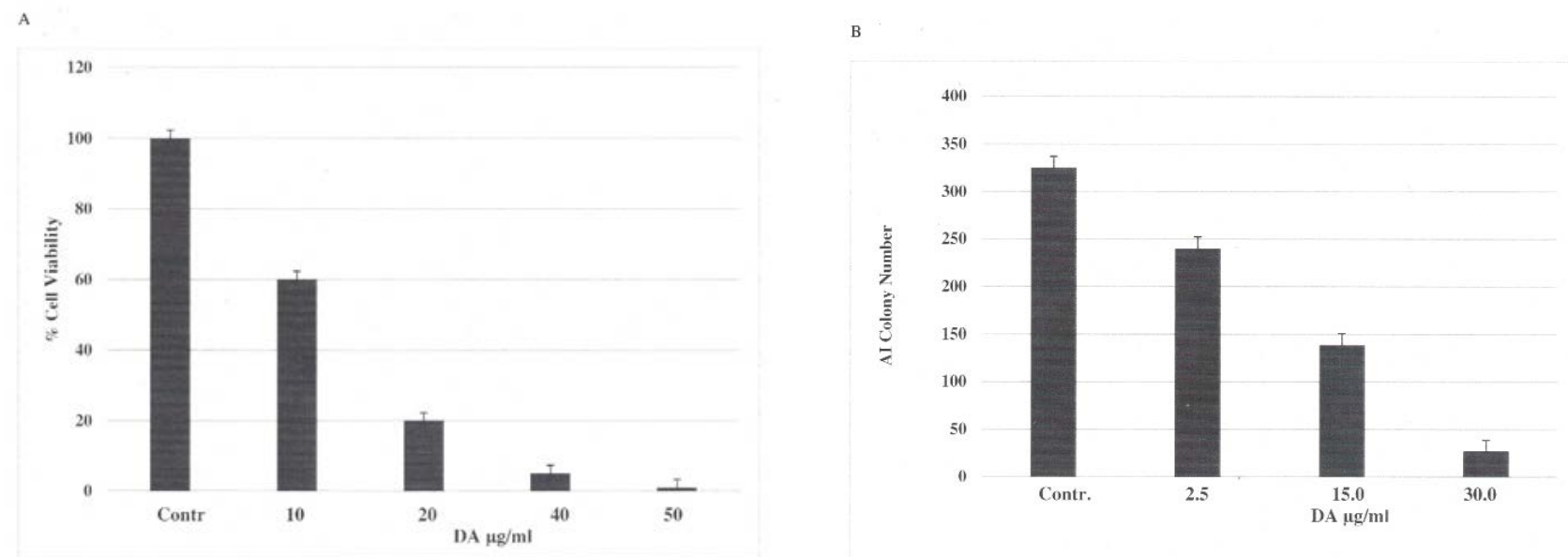

Figure 1. A: Effect of DA on cell viability of MDA-MB-231 cells. Cell viability (\%) determined at day 7 after seeding of $5.0 x 10^{3}$ cells. Data are presented as mean $\pm \mathrm{SD}, \mathrm{n}=3$ per treatment group. $\mathrm{DA} 10 \mu \mathrm{g} / \mathrm{ml}(\mathrm{P}=0.020)$. $\mathrm{DA} 40 \mu \mathrm{g} / \mathrm{ml}(\mathrm{P}=0.001)$. DA, Dipsacus asperoides; SD, standard deviation. B: Effect of DA on anchorage independent (AI) colony formation. Colony number determined at day 21 after seeding of $5.0 \times 10^{5}$ cells. Data are presented as mean \pm SD, $\mathrm{n}=3$ per treatment group. DA $15 \mu \mathrm{g} / \mathrm{ml}(\mathrm{P}=0.020)$. DA 30 $\mu \mathrm{g} / \mathrm{ml}(\mathrm{P}=0.001)$. DA, Dipsacus asperoides; SD, standard deviation.

With regard to the effect of DA on cell cycle progression, the primary data from the replicate experiments were obtained by flow cytometry. These data are presented as mean and standard deviation in Table 2. Treatment with DA induced a progressive
$\mathrm{G}_{2} / \mathrm{M}$ phase arrest of about a $71 \%(\mathrm{P}=0.030)$ for the $2.5 \mu \mathrm{g} / \mathrm{ml}$ group and about an $86 \%(\mathrm{P}=0.014)$ for the $15.0 \mu \mathrm{g} / \mathrm{ml}$ group, relative to the control group. The status of $\mathrm{G}_{2} / \mathrm{M}$ arrest obtained from one experiment is presented in Figure 2.

Table 2. Effect of Dispacus asperoides (DA) on cell cycle progression in MDA-MB-231cells

\begin{tabular}{|c|c|c|c|c|c|}
\hline Treatment & Concentration $(\mu \mathrm{g} / \mathrm{ml})$ & \multicolumn{2}{|c|}{ Cell cycle phase $^{a}$} & $\mathrm{P}$ & $\delta$ Control $\left(\% \mathrm{G}_{2} / \mathrm{M}\right)$ \\
\hline \multirow{4}{*}{ Control } & & $\% \mathrm{G}_{1}$ & $\% \mathrm{G}_{2} / \mathrm{M}$ & & \\
\hline & ---- & $39.9 \pm 2.3$ & $35.0 \pm 1.9$ & & ---- \\
\hline & 2.5 & $30.0 \pm 1.7$ & $60.0 \pm 2.9$ & 0.030 & $+71.4 \%$ \\
\hline & 15.0 & $29.8 \pm 1.9$ & $65.0 \pm 2.0$ & 0.014 & $+85.7 \%$ \\
\hline
\end{tabular}

${ }^{\text {a }}$ determined at day 3 post-seeding by FACS assay. Mean \pm SD, $n=3$ per treatment group. Data for $\%$ G2/M phase analyzed using ANOVA with Dunnett's post-hoc multiple comparison test.

$\delta$ Control, relative to control; DA, Dipsacus asperoides; FACS, fluorescence assisted cell sorting; SD, standard deviation; ANOVA, analysis of variance. 
A

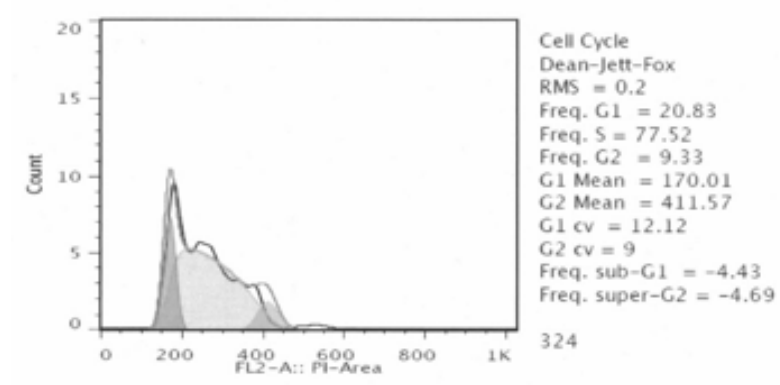

C

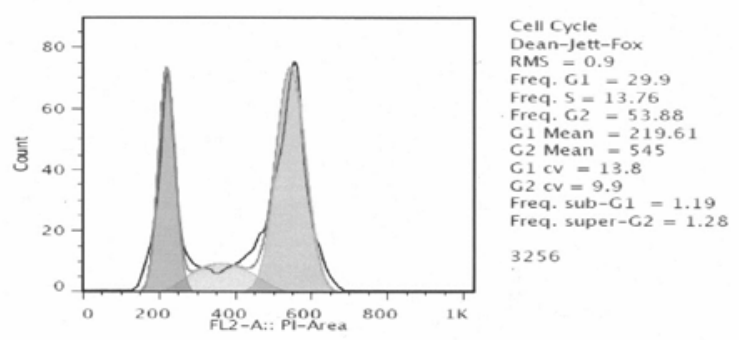

The experiment presented in Figure 3A examined the effect of DA on the expression of selected RAS down-stream effector proteins BRAF, MEK, ERK, and p-ERK. Treatment with $10 \mu \mathrm{g} / \mathrm{ml} \mathrm{DA}\left(\mathrm{IC}_{30}\right)$ and with $15 \mu \mathrm{g} / \mathrm{ml}$ DA $\left(\mathrm{IC}_{50}\right)$ for $48 \mathrm{~h}$. effectively inhibited the expression of BRAF, p-ERK and MEK in a dosedependent manner, relative to the control group.

The experiment presented in Figure 3B examined the effects of DA on the PI3K/AKT signaling. A 48h
B

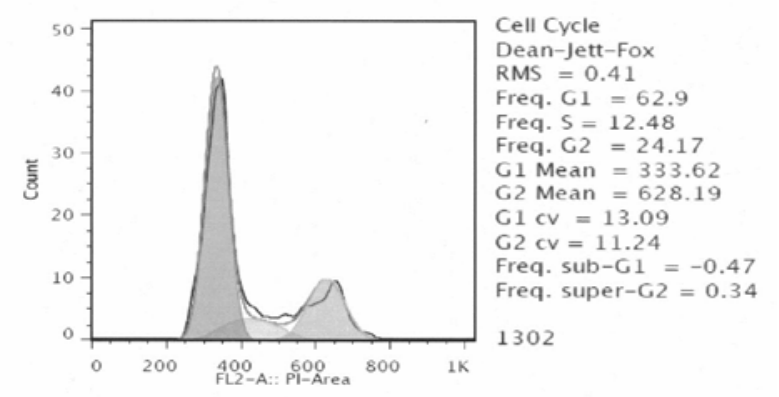

Figure 2: Effect of DA on cell cycle progression. Treatment with DA results in a dose- dependent increase in the frequency of cells in the $\mathrm{G}_{2}$ phase of the cell cycle. A. Control: 9.33\%. B.

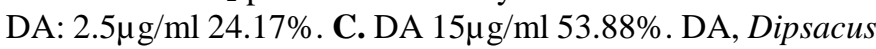
asperoides.

treatment with DA resulted in a dose dependent decrease in expression of pPI3K and pAKT, relative to the control group. The experiment presented in Figure 3C examined the effect of DA on the RB signaling pathway. A $48 \mathrm{~h}$ treatment with DA inhibited the expression of Cyclin D1, CDK4, CDK6 and p-RB in a dose dependent manner, relative to the control group, while the expression of CDKI p21 exhibited a dose dependent increase.
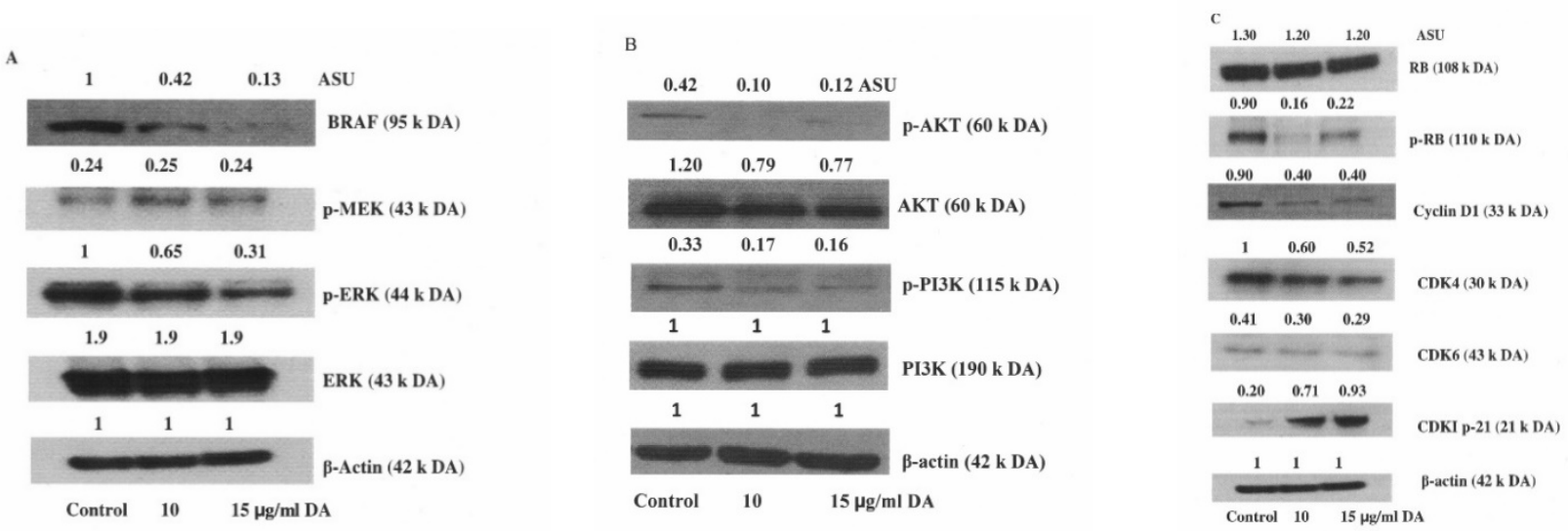

Figure 3. A. Effect of DA on the expression of RAS effector proteins. The expression of BRAF, MEK and p-ERK exhibit a DA dose dependent inhibition. DA, Dipsacus asperoides. B. Effect of DA on AKT/ PI3K signaling. The expression of pAKT and pPI3K exhibit a DA dose dependent decrease in response to treatment with DA. DA, Dipsacus asperoides; AKT, protein kinase B; PI3K, phosphoinositide 3 kinase. C. Effect of DA on the RB signaling pathway. The expression of pRB, cyclin D1, CDK4 and CDK6 is inhibited, while that of CDKI p21 is increased in response to treatment with DA. DA, Dipsacus asperoides; RB; retinoblastoma; CDK; cyclin dependent kinase.

As for the effect of DA on cellular apoptosis, an experiment was conducted which is presented in Figure $4 \mathrm{~A}$ and $4 \mathrm{~B}$. In response to the treatment with DA at the concentrations of $15 \mu \mathrm{g} / \mathrm{ml}$ and $30 \mu \mathrm{g} / \mathrm{ml}$, the sub $\mathrm{G}_{0}$ (apoptotic cell) population exhibited about a 3.3-fold ( $\mathrm{P}=0.014)$ to about a 3.6-fold $(\mathrm{P}=0.001)$ progressive dose dependent increase, relative to the control group (Figure 4A). In parallel with the data on apoptotic cell population, caspase 3/7 activity exhibited about a 7 -fold increase $(\mathrm{P}=0.001)$ for the $15 \mu \mathrm{g} / \mathrm{ml}$ group and about an 8.5 -fold increase $(\mathrm{P}=0.005)$ for the $30 \mu \mathrm{g} / \mathrm{ml}$ group, relative to the control group (Figure 4B). 


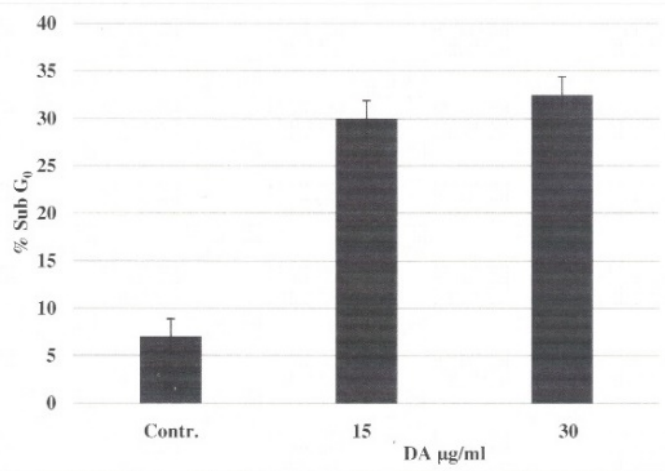

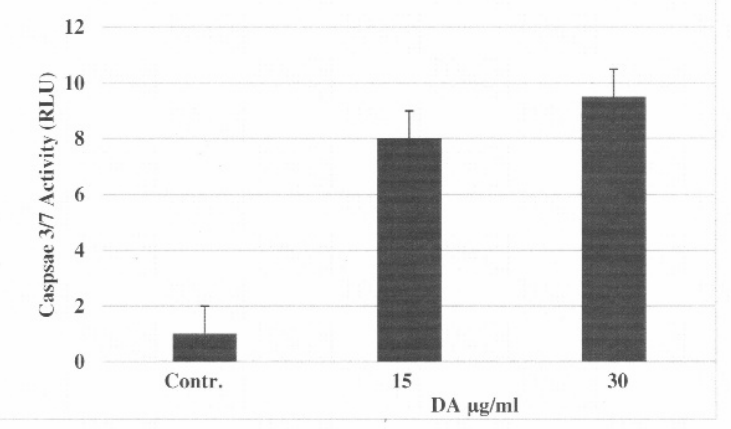

Figure 4. A. Effect of DA on the Sub $G_{0}$ phase of the cell cycle. Treatment with DA induces a dose dependent increase in the number of cells at the Sub $G_{0}$ (apoptotic) phase. Data is presented as mean \pm SD, $n=3$ per treatment group. DA $15 \mu g / \mathrm{ml}$ $(\mathrm{P}=0.014)$. DA $30 \mu \mathrm{g} / \mathrm{ml}(\mathrm{P}=0.001)$. DA, Dipsacus asperoides; SD, standard deviation. B. Effect of DA on Caspase 3/7 activity. Treatment with DA induces a dose dependent increase in the caspase activity. Data are presented as mean $\pm \mathrm{SD}, \mathrm{n}=3$ per treatment group. DA $15 \mu \mathrm{g} / \mathrm{ml}(\mathrm{P}=0.001)$. DA $30 \mu \mathrm{g} / \mathrm{ml}(\mathrm{P}=0.005)$. DA, Dipsacus asperoides; SD, standard deviation.

\section{DISCUSSION}

Treatment of choice for TNBC molecular subtype includes anthracycline/taxol or cisplatin based chemotherapy, or survival pathway based PARP, AKT and m-TOR selective small molecule inhibitor mediated targeted therapy.,5,50,21 These treatment options are associated with systemic toxicity, acquired tumor resistance and emergence of drug resistant cancer stem cells, leading to therapyresistant disease progression. ${ }^{6,20-22}$ Published studies on cellular models for Luminal A and TNBC molecular subtypes have provided evidence that several Chinese nutritional herbs with distinct mechanisms of action display growth inhibitory effects. ${ }^{11-17}$ The present study utilizes the MDA-MB231 model for TNBC to examine the growth inhibitory effects of the Chinese nutritional herb DA, and to identify relevant molecular mechanisms for its efficacy.

In traditional Chinese medicine, herbal formulations are often prepared by brewing the herbs in water and the water-soluble extract is provided to patients for oral consumption. Therefore, to simulate the clinical setting, a non-fractionated aqueous extract of DA was used in the present study.

The treatment of the MDA-MB-231 cells with DA produced cytostatic growth arrest and inhibited AI colony formation in vitro. AI colony formation represents a specific characteristic of carcinomaderived tumorigenic cells, and, therefore, represents an in vitro surrogate marker for in vivo tumor growth. Collectively, these data provide evidence that DA effectively inhibits growth and reduces risk for tumor development in the present model. These data are consistent with the effects of several other nutritional herbs in the TNBC model. ${ }^{16,17}$ It is notable that compared to the MDA-MB-231 cells, the nontumorigenic 184-B5 cells required substantially higher concentrations of DA to inhibit growth as described in the results section. These observations on distinct growth inhibitory effects on tumorigenic and non-tumorigenic cells provide evidence for a greater sensitivity of the carcinoma derived cells to DA compared to the non-tumorigenic cells.

The experiment designed to examine the effect of DA on the cell cycle progression revealed that treatment with DA induced a progressive arrest of the cells in the $G_{2} / M$ phase of the cell cycle. This effect appears to be distinct for DA, since other nutritional herbs, such as Tabebuia avellandae (TA) and Cornus officinalis (CO), induced $\mathrm{G}_{1}$ arrest in the present model. ${ }^{16,17}$ Collectively, these data suggest that the selected nutritional herbs affect distinct phases of cell cycle progression. It is notable that DA-induced $\mathrm{G}_{2} / \mathrm{M}$ arrest is similar to that of the chemotherapeutic agent taxol which also affects $\mathrm{G}_{2} / \mathrm{M}$ phase and functions as a potent mitotic inhibitor. ${ }^{23,24}$

The experiment to examine the effect of DA on cellular apoptosis provided evidence that treatment with DA increased the cell population in the sub $\mathrm{G}_{0}$ (apoptotic) phase of the cell cycle and also increased the pro-apoptotic caspase 3/7 activity. These data, taken together, provide plausible mechanistic leads to suggest that DA may induce cellular apoptosis in the present TNBC model. Furthermore, these data provide a basis for future investigations into identifying relevant pathways and susceptible molecular targets that may be responsible for induction of cellular apoptosis.

Cell survival pathway relevant to the oncogenic RAS isoforms results in hyper-proliferation that is 
predominantly effective via Raf/MEK/ERK signaling axis, and represents a prominent driver of tumorigenesis. ${ }^{25-29}$ The experiment designed to examine the effect of DA on the downstream effectors of RAS signaling pathway clearly demonstrated that DA at the cytostatic concentrations specifically inhibits the expression of BRAF, MEK and pERK, while that of total ERK remains essentially unaltered. This observation raises the possibility that DA treatment may result in functional inhibition of ERK signaling, rather than ERK synthesis.

It is generally accepted that the RAS effector signaling together with the $\mathrm{PI} 3 \mathrm{~K} \alpha / \mathrm{Akt} / \mathrm{m}-\mathrm{TOR}$ pathways represent major survival pathways in breast cancer cells. ${ }^{25}$ These pathways are susceptible to small molecule inhibitors and exhibit demonstrable clinical efficacy., $4,52,21$ Specifically, down-stream effectors BRAF, MEK and ERK represent more effective targets for selective small molecule inhibitors of oncogenic functions of RAS, since the gain of function oncogenic RAS remains essentially an intractable pharmacologic target. However, recent evidence on the efficacy of mutant RAS selective small molecule inhibitor suggests that downregulation of RAS-mediated MAPK signaling is due to the persistence of GDP bound Ras-p21. ${ }^{29}$

The survival pathways are activated in cisplatin resistant TNBC cells, ${ }^{30}$ and targeting these signaling pathways results in enhanced efficacy of the first-line treatment options for chemotherapy. ${ }^{31,32}$ Present data on the effect of DA on the survival pathways via inhibition of pPI3K and pAKT indicate that DA affects phosphorylation/activation of these signaling molecules, and provide mechanistic leads for the efficacy of a nontoxic nutritional herb against survival of chemotherapy resistant TNBC. Consistent with this interpretation, published evidence suggests that an extract from the rosemary herb inhibits proliferation and survival via inhibition of phosphorylation/activation of AKT and mTOR signaling in the MDAMB-231 model. ${ }^{33}$ It is also notable that agents that regulate the PI3K/AKT signaling pathway frequently exhibit PI3K/AKT independent regulation of the mTOR/mTORC1 axis. $^{34,35}$ Thus, the present data provide novel clinically translatable mechanistic leads for the effect of DA on the RAS, PI3K $\alpha$ and AKT signaling. Additional studies to evaluate the specificity and sensitivity of DA for these mechanistic leads and investigations on the mTOR signaling pathway should provide a scientifically robust basis for future studies aimed at identifying susceptible mechanistic pathways and molecular targets for the inhibitory efficacy of DA.

Tumor suppressive function of RB via Cyclin D1CDK4/CDK6- pRB-E2F pathway is frequently compromised in the TNBC subtype. ${ }^{20,21}$ In this pathway, cyclin-dependent kinase inhibitors (CDKI) $\mathrm{p} 16^{\mathrm{INK} 4}, \mathrm{p} 21^{\text {cip1/Waf1 }}$ and $\mathrm{p} 27^{\mathrm{Kip} 1}$ as well as cyclin D represent functionally important signaling molecules. ${ }^{36-41}$ The data on the effects of DA on RB signaling pathway revealed that the treatment with DA resulted in a dose dependent inhibition in cyclin D1, CDK4, CDK6 and p-RB. In contrast, the expression of CDKI p21 $1^{\text {cip1/waf1 }}$ increased depending on the concentration of DA. Previously presented preliminary data ${ }^{42}$ together with the present data provide evidence for mechanistic leads that RAS, $\mathrm{PI} 3 \mathrm{~K} / \mathrm{AKT}$ and RB signaling pathways may represent relevant molecular targets for the efficacy of DA in the present model system, and that DA functions as a natural inhibitor of these pathways.

Regarding the role of various CDKIs, published evidence suggests sequestering of $\mathrm{p} 21^{\mathrm{cip} 1 / \mathrm{waf} 1}$ and p27 ${ }^{\text {Kip1 }}$ via the physiologically relevant non-catalytic function of cyclin D1-CDK4/CDK6 complex. ${ }^{37,39,41}$ Thus, increased p21 expression may suggest involveement of its sequestering. In this context, it is also noteworthy that anti-proliferative and pro-apoptotic effects of gallic acid involves up-regulation of the p38 mitogen activated protein kinase /p21/p27 axis in the MDA-MB-231 model, ${ }^{43}$ and that benzofuran derivatives induce apoptosis via upregulation of $\mathrm{p} 21^{\mathrm{cip} 1 / \text { waf1 }}$ in the breast cancer models independent of their p53 status. ${ }^{44}$

The present cellular model for TNBC represented by the MDA-MB-231 cell line expresses TP53 ${ }^{\mathrm{R} 280 \mathrm{~K}}$ gain of function mutation and exhibits enhanced survival via up-regulated migration and invasion of the cells, indicating p53 as a putative therapeutic target. ${ }^{45,46}$ CDKI p21 is commonly associated with the tumor suppressive function of wild type $p 53$. Thus, up-regulation of $\mathrm{p} 21^{\text {cip } 1 / \text { waf1 }}$ by DA in $p 53$ mutant MDA-MB-231 cells is intriguing. However, upregulation of $\mathrm{p} 21^{\text {cip1/waf1 }}$ in TNBC models by Gallic acid, ${ }^{43}$ and benzofuran, ${ }^{44}$ suggests that similar to these agents, DA may also function independently of mutant $p 53$. Consistent with this interpretation, the naturally occurring quinone, $\beta$-lapachone exhibits growth inhibitory efficacy via inhibition of RB phosphorrilation and upregulation of $\mathrm{p} 21^{\text {cip1/waf1 }}$ independent of p53 status in human prostate cancer cells. ${ }^{47}$ Collectively, these lines of evidence provide a plausible interpretation of the present data and may identify additional functional leads for the efficacy of DA.

Small molecule inhibitors for CDK4/6 in combination with aromatase inhibitors have provided evidence for clinical efficacy in estrogen receptor positive, human epidermal growth factor receptor negative advanced breast cancer. ${ }^{48-50}$ In addition, recent evidence has demonstrated the efficacy of CDK4/6 inhibitor palbociclib (brand name Ibrance, Pfizer) in cellular models for TNBC, ${ }^{51}$ and expression 
of EGFR and RB has been associated with enhanced efficacy of a combination of EGFR inhibitor Erlotinib and CDK4/6 inhibitor palbociclib in TNBC. ${ }^{52}$ Another CDK4/6 inhibitor, ribociclib (brand name Kisqali, Novartis) exhibits anti-proliferative and proapoptotic effects on the MDA-MB-231 model by inhibiting the CDK4/6-cyclinD-RB-E2F pathway, ${ }^{53}$ and CDK4/6 inhibition in combination with PI3Ka inhibition significantly increases cell cycle arrest and cellular apoptosis in several TNBC models. ${ }^{54}$ However, acquired resistance to CDK4/6 inhibitors, ${ }^{55}$ emphasizes identification of therapeutic alternatives. In this context, DA mediated inhibition of CDK4/6 in the present study identifies a novel mechanistic link for its efficacy in TNBC.

\section{CONCLUSION}

In conclusion, the present data have provided evidence for growth inhibitory efficacy of DA functioning via RAS, PI3K, AKT and RB signaling pathways in the present model for TNBC. In this context, it is conceivable that the non-fractionated aqueous extract from DA may contain multiple watersoluble constituents that are likely to be effective via

\section{REFERENCES}

1. American Cancer Society-Facts \& Figures 2021. Atlanta: American Cancer Society, 2021. Available at: https://www.cancer.org/content/dam/cancerorg/research/cancer-facts-and-statistics/annualcancer-facts-and-figures/2021/cancer-facts-andfigures-2021.pdf

2. Sorlie T, Perou CM, Tibshirany R, Aas T, Geisler S, Johnsen $\mathrm{H}$, et al. Gene expression patterns of breast carcinomas distinguish tumor subclasses with clinical implications. Proc. Natl. Acad. Sci. USA. 2001; 98: 10869-10874. doi: 10.1073/pnas.191367098.

3. Baselga J, Swain SM. Novel anti-cancer agents: Revisiting ERBB2 and discovering ERBB3. Nat. Rev. Cancer. 2009; 9: 463-475. doi: 10.1038/nrc 2656.

4. Dinh P, Satirou C, Piccart MJ. The evaluation of treatment strategies: Aiming at the target. Breast. 2007; 16 (suppl. 2): S10-S16. doi: 10.1016/j. breast. 2007.07.032

5. Anders CK, Winer EP, Ford JM, Dent R, Silver DP, Sledge GW, et al. Poly (ADP-ribose) inhibition: Targeted therapy for triple negative breast cancer. Clin. Cancer Res. 2010; 16: 4702-4710. doi: 10.1158/1078-0432.CCR-10-0939.

6. Dean M, Fojo T, Bates S. 2005; Tumor stem cells and drug resistance. Nat. Rev. Cancer. 2005; 5: 275-284. doi: 10.1038/nrc 1590.

7. Tindle HA, Davis RB, Phillips RL, Eisenburg DM. Trends in the use of complementary and alternative medicines by US adults: 1997-2002. Altern. Ther. Health Med. 2005; 11: 42-49. doi: Not available. synergistic interaction. Thus, it is not possible to ascribe the growth inhibitory effect to a specific bioactive agent. This study validated a facile mechanism-based experimental approach to evaluating the efficacy of nutritional herbs as testable alternatives in chemo-endocrine therapy resistant breast cancer for secondary prevention/therapy. Furthermore, the present study provided a scientifically robust rationale for future research directions involving in vivo investigations on tumors developed from the xeno-grafted TNBC cells where the status of the relevant molecular pathways may identify mechanistic targets for anti-tumorigenic efficacy of nutritional herbs.

\section{ACKNOWLEDGEMENTS}

This research was supported by philanthropic contributions to the American Foundation for Chinese Medicine from the Randall and Barbara Smith Foundation, and the Sophie Stenbeck Family Foundation.

\section{CONFLICT OF INTEREST}

The authors declare that there is no conflict of interest.

8. Molassiotis A, Scott JA, Kearney A, Kearney N. Complementary and alternative medicine use in breast cancer patients in Europe. Support Care Cancer. 2006; 14: 260-267. doi: 10.1007/sco520005-0883-7.

9. Hyler LK, Chin S, Chui BK: The use of complementary and alternative medicine among patients with locally advanced breast cancer: A descriptive study. BMC Cancer. 2006; 6: 39-46. doi: Not available.

10. Ye L, Jia Y, Ji KE, Saunders AJ, Xue K, Ji J, et al. Traditional Chinese medicine in the prevention and treatment of breast cancer and cancer metastasis. Oncol. Lett. 2015; 10: 1240-1250. doi: 10.3892/ol.2015.3459.

11. Mukherjee B, Telang N, Wong GYC. Growth inhibition of estrogen receptor positive human breast cancer cells by Taheebo from the inner bark of Tabebuia avellandae tree. Int. J. Mol. Med. 2009; 24: 253-260. doi: 10.3892/ijmm.00000228.

12. Li G, Sepkovic DW, Bradlow HL, Telang NT, Wong GYC: Lycium barbarum inhibits growth of estrogen receptor positive human breast cancer cells by favorably altering estradiol metabolism. Nutrition \& Cancer. 2009; 61: 408-414. doi: 10.1080/0163558082585952.

13. Telang NT, Li G, Sepkovic DW, Bradlow HL, Wong GYC. Anti-proliferative effects of Chinese herb Cornus officinalis in a cell culture model for estrogen receptor positive clinical breast cancer. Mol. Med. Rep. 2012; 5: 22-28. doi: 10.3892/mmr.2011.617. 
14. Telang N, Li G, Sepkovic D, Bradlow HL, Wong GYC. Comparative efficacy of extracts form Lycium barbarum bark and fruit on estrogen receptor positive human mammary carcinoma MCF-7 cells. Nutrition \& Cancer. 2014; 66: 278-284. doi: 10.1080/01635581.2014.864776.

15. Telang N, Li G, Katdare M, Sepkovic D, Bradlow L, Wong GYC. Inhibitory effects of Chinese nutritional herbs in isogenic breast carcinoma cells with modulated estrogen receptor function. Oncol. Lett. 2016; 12: 3949-3957. doi: 10.3892/ol.2016.5197.

16. Telang NT, Nair HB, Wong GYC. Growth inhibitory efficacy of Tabebuia avellanedae in a model for triple negative breast cancer. Arch. Breast Cancer 2021; 8: 203-209. doi: 10.32768/abc.202183203-209.

17. Telang N, Nair HB, Wong GYC. Growth inhibitory efficacy of Cornus officinalis in a cell culture model for triple negative breast cancer. Oncol. Letts. 2019; 17: 5261-5266. doi: 10.3892/ol.2019.10182.

18. Neve RM, Chin K, Fridyand J, Yeh J, Baehner FL, Fevr T, et al. A collection of breast cancer cell lines for the study of functionally distinct cancer subtypes. Cancer Cell. 2006; 10: 515-527. doi: 10.1016/jccr.2006.10.008.

19. Subik K, Lee J-F, Baxter L, Strzepak T, Costello D, Crowley $\mathrm{P}$, et al. Expression patterns of ER, PR, HER2, CK5/6, EGFR, Ki67 and AR by immuonohistochemical analysis in breast cancer cell lines. Breast Cancer (Aukl.) 2010; 4: 35-41. doi: Not available.

20. Hudis CA, Gianni L. Triple negative breast cancer: An unmet medical need. Oncologist Suppl. 2011; 1: 1-11. doi: 10.1634/theoncologist.2011-s1-01.

21. Lin NU, Vanderplast A, Hughes ME, Theriault RL, Edge SB, Wong U-N, et al. Clinico-pathologic features, patterns of recurrence and survival among women with triple negative breast cancer in the National Comprehensive Cancer Network. Cancer. 2012; 218: 5463-5472. doi: 10.1002/cncr.27581.

22. Telang N. Putative cancer initiating stem cells in cell culture models for molecular subtypes of clinical breast cancer. 2015; Oncol. Lett. 10: 3840-3846. doi: 10.3892/ol.2015.3780.

23. Cortes J, Baselga J. Targetting the microtubules in breast cancer beyond taxanes: the epothilones. Oncologist. 2007; 12: 271-280. doi: 10.1634/theoncologist.12-3-271.

24. Thomas G, Sreeja JS, Gireesh KK, Gupta H, Manna TK. +TIP EB1 downregulates paclitaxel-induced proliferation inhibition and apoptosis in breast cancer cells through inhibition of paclitaxel binding to microtubules. Int. J. Oncol. 2015; 46: 133-146. doi: 10.3892/ijo.2014.2701.

25. Mirzoeva OK, Das D, Heiser LM, Bhattacharya S, Sivak D, Gendelman R, et al. Basal subtype and MAPK/ERK kinase (MEK)-phosphoinositide 3kinase feedback signaling determine susceptibility of breast cancer cells to MEK inhibition. Cancer Res. 2009; 69: 565-572. doi: 10.1158/0008-5472.CAN08-3389.
26. Collisson EA, Trejo CL, Silvo JM, Gu S, Karkola JE, Heiser LM, et al. A central role of RAF-MEK-ERK signaling in genesis of pancreatic ductal adenocarcinoma. Cancer Discov. 2012; 2: 685-693. doi: 10.1158/2159-8290.CD-11-0347.

27. Nussinov R, Tsai C-J, Jang H. Oncogenic Ras isoforms signaling specificity at the membrane. Cancer Res. 2018; 78: 593-602. doi: 10.1158/00085472.CAN-17-2727.

28. Yaeger R, Solit DB. Overcoming adaptive resistance to KRAS inhibitors through vertical pathway targeting. Clin. Cancer Res. 2020; 26: 1538-1540. doi: 10.1158/1078-0432.CCR-19-4060.

29. Ryan MB, Face de la Cruz F, Phat S, Meyers DT, Wong E, Shahzade HA, et al. Vertical pathway inhibition overcomes adaptive feedback resistance to KRAS G12c inhibition. Clin. Cancer Res. doi; Not available. PMID: 31776128.

30. Gohr K, Hamacher A, Engelke LH, Kassak MU. Inhibition of PI3K/AKT/mTOR overcomes cisplatin resistance in the triple negative breast cancer cell line HCC38. BMC-Cancer. 2017; 17: 711. doi: 10.1186/s 12885-017-3695-5.

31. Massihnia D, Galvano A, Fanale D, Perez A, Casiglia $\mathrm{M}$, Incorvaia L, et al. Triple negative breast cancer: Shedding light on to the role of PI3K/AKT/mTOR pathway. Oncotarget. 2016; 7: 60712-60722. doi: 10.18632/oncotarget.10858.

32. Costa RLB, Han HS, Gradishar WJ. Targeting the $\mathrm{PI} 3 \mathrm{~K} / \mathrm{AKT} / \mathrm{mTOR}$ pathway in triple negative breast cancer: A review. Breast Cancer Res. Treat. 2018; 169: 397-406. doi: 10.1007/s10549-018-4697-Y.

33. Jaglanian A, Tsiani E. Rosemary extract inhibits proliferation, survival, AKT, and mTOR signaling in the triple negative breast cancer cells. Int. J. Mol. Sci. 2020; 21: 810. doi: 10.3390/ijms21030810.

34. Memmott RM, Dennis PA. Akt-dependent andindependent mechanisms of mTOR regulation in cancer. Cell Signal. 2009; 21: 656-664. doi: 10.1016/j.cellsig.2009.01.004.

35. Jegg AM, Ward TM, Iorns E, Hoe N, Zhou J, Liu X, et al. PI3K independent activation of mTORC1 as a target in lapatinib-resistant ERBB2 + breast cancer cells. Breast Cancer Res. Treat. 2012; 136: 683-692. doi: 10.1007/s10549-012-2252-9.

36. Cox LA, Chen G, Lee EY. Tumor suppressor genes and their role in breast cancer. Breast Cancer Res. Treat. 1994; 32: 19-38. doi: 10.1007/BF00666203.

37. Burkhart DL, Sage J. Cellular mechanisms of tumor suppression by the retinoblastoma gene. Nat. Rev. Cancer. 2008; 8: 671-682. doi: 10.1038/nrc 2399.

38. Bosco EE, Knudson ES. RB in breast cancer: At the crossroads of tumorigenesis and treatment. Cell Cycle. 2007; 6: 667-671. doi: 10.4161/cc.6.6.3988.

39. Sherr CJ, Roberts JM. CDK inhibitors: positive and negative regulators of G1 phase progression. Genes \& Dev. 1999; 13: 1501-1512. doi: 10.1101/gad.13.12.1501.

40. Musgrove EA, Caldon CE, Barraclough J, Stone A, Sutherland RL. Cyclin D as a therapeutic target in 
cancer. Nat. Rev. Cancer. 2011; 11: 558-572. doi: 10.1038/nrc 3090.

41. Van Arsdale T, Boschoff C, Arndt KT, Abraham RT. Molecular pathways: Targeting the Cyclin D-CDK 4/6 axis for cancer treatment. Clin. Cancer Res. 2015; 21: 2905-2910. doi: 10.1158/1078-0432.CCR-140816.

42. Telang N, Nair HB, Wong, GYC. Efficacy of Dipsacus asperoides (DA) in a model for triple negative breast cancer. Cancer Res. 2016; 76 (Suppl.): SABCS Abstract \# P4-13-04. doi: not available.

43. Lee HL, Lin CS, Kao SH, Chou MC. Gallic acid induces G1phase arrest and apoptosis of triple negative breast cancer cell MDA-MB-231 via p38 mitogen-activated protein kinase /p21/p27 axis. Anticancer Drugs. 2017; 28: 1150-1156. doi: 10.1097/CAD.0000000000000565.

44. Giordano C, Rovito D, Barone I, Moncuso R, Bonofiglio D, Giordano F, et al. Benzofuran-2-acetic ester derivatives induce apoptosis in breast cancer cells by upregulating $\mathrm{p} 21^{\mathrm{Cip} / \mathrm{WAF} 1}$ gene expression in p53-independent manner. DNA Repair. 2017; (Amst.) 51: 20-30. doi: 10.1016/jdnarep.2017.01.006.

45. Muller PAJ, Vousden KH. Mutant p53 in cancer: New functions and therapeutic opportunities. Cancer Cell. 2014; 25: 304-317. doi: 10.1016/j.ccr.2014.01.021.

46. Hui L, Zheng Y, Yan Y, Bargonetti J, Foster DA. Mutant p53 in MDA-MB-231 breast cancer cells is stabilized by elevated phospholipase D activity and contributes to survival signals generated by phospholipase D. Oncogene. 2006; 25: 7305-7310. doi: 10.1038/sj.onc.1209735.

47. Choi YH, Kang HS, Yoo MA. Suppression of human prostate cancer cell growth by $\beta$-Lapachone via down-regularion of pRB phosphorylation and induction of CDK inhibitor p21 (WAF1/CIP1). J. Biochem. Mol. Biol. 2003; 36: 223-229. doi: 10.5483/bmbrcp.2003.36.2.223.
48. Boer K. Impact of palbociclib combinations on treatment of advanced estrogen receptorpositive/human epidermal growth factor receptor2negative breast cancer. Onco Targets Ther. 2016; 11: 6119-6125. doi: 10.2147/OTT.s77033.

49. Alves CL, Elias D, Lyng M, Bak M, Kirkegaard T, Lykkesfeldt AE et al. High CDK6 protects cells from Fulvestrant-mediated apoptosis and is a predictor of resistance to Fulvestrant in estrogen receptor-positive metastatic breast cancer. Clin. Cancer Res. 2016; 22: 5514-5526. doi: 10.1158/1078-0432.CCR-15-1984.

50. Klein ME, Kovatcheva M, Davis LE, Tap WD, Koff A. CDK4/6 inhibitors: The mechanism of action may not be as simple as once thought. Cancer Cell. 2018; 34: 9-20. doi: 10.1016/j.ccell.2018.03.023.

51. Asghar US, Barr AR, Cutts R, Beany M, Babina I, Sampath D, et al. Single cell dynamics determines response to CDK4/6 inhibition in triple negative breast cancer. Clin. Cancer Res. 2017; 23: 55615572. doi: 10.1158/1078-0432.CCR-17-0369.

52. Foidart P, Yip C, Redenmacher J, Blacher S Lienard M, Montero-Ruiz L, et al. Expression of MT4-MMP, EGFR and RB in triple negative breast cancer strongly sensitizes tumors to erlotinib and palbociclib combination therapy. Clin. Cancer Res. 2019; 25: 1838-1850. doi: 10.1158/1078-0432.CCR-18-1880.

53. Li T, Xiong Y, Wang Q, Chen F, Zeng Y, Yu X, et al. Ribociclib (LEE011) suppresses cell proliferation and induces apoptosis of MDA-MB-231 cells by inhibiting CDK4/6-cyclin D-Rb-E2F pathway. Artif. Cells Nanomed. Biotechnol. 2019; 47: 4001-4011. doi: 10.1080/21691401.2019.1670670.

54. Teo ZL, Versaci S, Dushyanthen S, Caramia F, Savas $\mathrm{P}$, Mintoff CP, et al. Combined CDK4/6 and PI3K $\alpha$ inhibition is synergistic and immunogenic in triplenegative breast cancer. Cancer Res. 2017; 77: 63406352. doi: 10.1158/0008-5472.CAN-17-2210.

55. De Leeuw R, McNair C, Schiewer MJ, Neupane NP, Brand LJ, Augello MA, et al: MAPK reliance via acquired CDK4/6 inhibitor resistance in cancer. Clin. Cancer Res. 2018; 24: 4201-4214. doi: 10.1158/1078-0432. CCR-18-0410.

\section{How to Cite This Article}

Telang N, Nair HB, Wong GYC. Anti-proliferative and pro-apoptotic effects of Dipsacus asperoides in a cellular model for triple-negative breast cancer. Arch Breast Cancer. 2022; 9(1):66-75.

Available from: https://www.archbreastcancer.com/index.php/abc/article/view/450 